\title{
CLASSIFICATION OF TRANSIENT PHENOMENA IN DISTRIBUTION SYSTEM USING WAVELET TRANSFORM
}

\begin{abstract}
Alireza Sedighi *
An efficient procedure for classification of transient phenomena in distribution systems is proposed in this paper. The proposed method has been applied to classify some transient phenomena such as inrush current, load switching, capacitor switching and single phase to ground fault. The new scheme is based on wavelet transform algorithm. All of the events for feature extraction and test are simulated using Electro Magnetic Transient Program (EMTP). Results show high accuracy of proposed method.
\end{abstract}

K e y w o r d s: electric distribution system, switching transients, transient analysis, wavelet transforms

\section{INTRODUCTION}

Classification of transient phenomena on electric distribution systems is a challenging problem. Protective relays capable of identifying disturbances correctly, reliably and fast [1-5] must be applied to differentiate between transient disturbances due to events such as transformer inrush, fault, load and capacitor switching. Transients due to capacitor bank switching and the related power quality problems are discussed in [6-8]. Discrimination between magnetizing inrush current and fault is studied in [9-13]. Load switching that causes a transient event is investigated in $[14,15]$. The feasibility of applying unsupervised learning techniques to the classification of transient events in distribution network is also discussed in [15]. The specific unsupervised learning schemes applied include the self-organizing mapping scheme introduced by Kohonen as well as a model based on adaptive resonance theory. In the previous research discrimination and identification only were applied for one or two types of transient phenomena such as capacitor transient, load switching transient, magnetizing inrush current. The aim of this paper is the classification of many types of transients common in distribution systems that includes inrush current, load switching, capacitor switching and single phase to ground fault using wavelet transform.

Simulation studies have been performed using ATPEMTP for different types of single phase to ground faults, load switching, capacitor switching and no load transformer switching for a typical primary $20 \mathrm{kV}$ radial distribution feeder. In these tests three phase currents are recorded at the $\mathrm{HV} / \mathrm{MV}$ substation with a $20 \mathrm{kHz}$ sampling rate. The results show effectiveness of the proposed technique. In the next section wavelet transform is explained. The third section shows simulation results for feature extraction. Proposed procedure is in the forth section and finally test results are in the fifth section.

\section{ABOUT APPLICATION OF WAVELET TRANSFORMS IN CLASSIFICATION}

The wavelet transform, introduced almost 30 years ago, has been used in several fields of signal and image processing. It has been also applied in the power systems field. Some illustrative examples of application of wavelet transforms in power systems are

- power system transients [16],

- power quality assessment [17],

- modeling of system components in wavelet domain [18].

A brief introduction to wavelet transforms is given here. A more detailed description can be found in [19, 20].

The transform of a continuous signal is defined as the sum over all time of the signal multiplied by the scaled, shifted versions of a wavelet function $\psi$, the mother wavelet.

$$
C(\text { scale }, \text { position })=\int_{-\infty}^{\infty} f(t) \psi(\text { scale }, \text { position }, t) \mathrm{d} t
$$

This results in many wavelet coefficients $C$, which are a function of scale (related to frequency) and position (related to time).

In the discrete scope of the approach used here, the discrete dyadic wavelet transform was employed where scale $=2^{m}$ and position $=n 2^{m}$ ( $n$ and $m$ integer numbers) are used. Function $\psi(t)$ is chosen to constitute an orthonormal basis $\psi_{m, n}$ of the wavelet system,

$$
\psi_{m, n}(t)=2^{-\frac{m}{2}} \psi\left(2^{-m} t-n\right) .
$$

Then, any signal $f(t)$ can be expressed as

$$
f(t)=\sum_{n} \sum_{m} d_{m, n} \psi_{m, n}(t)
$$

where $d_{m, n}$ is the inner product with the orthonormal basis,

$$
d_{m, n}=\left\langle f, \psi_{m, n}\right\rangle \text {. }
$$

* Electrical and Computer Engineering Department, Yazd University, Yazd, Iran; sedighi@yazduni.ac.ir 


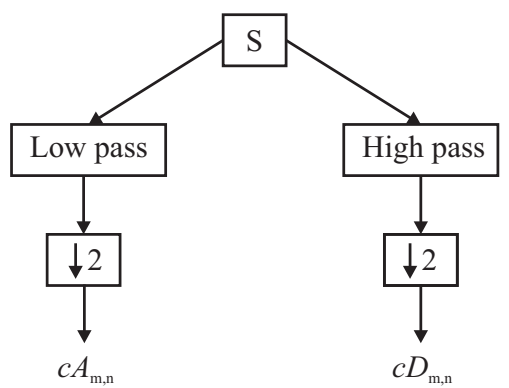

Fig. 1. Decomposition stage in approximation A1 and detail D1 in discrete wavelet transform

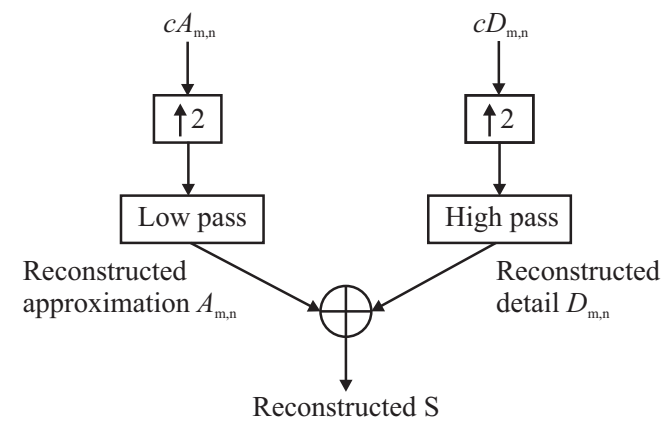

Fig. 2. Reconstruction of approximation and detail in discrete wavelet transform

An efficient way to compute the $d_{m, n}$ coefficients was developed by means of an algorithm known in the signal processing field as channel sub band order using Quadrate Mirror Filter (QMF), the filter bank formulation of the wavelet system: high pass filter related to mother wavelet, and low pass filter related to scaling function. The output sequence of each filter is down sampled to avoid redundant information. This way it is possible to carry out the multi resolution sub band decomposition (analysis) and reconstruction (synthesis). For each decomposition stage, the approximation coefficients $c A_{m, n}$ are obtained from the low pass filter and detail coefficients $c D_{m, n}$ are obtained from the high pass filter in Fig. 1, where the first decomposition stage of signal $S$ is shown.

In the discrete wavelet transform, the decomposition process can be iterated, with successive approximation (low pass wavelet branch) being decomposed in turn. This makes up the decomposition algorithm tree.

For reconstruction, stretching and filtering are necessary using the related filter bank. The reconstruction stage is shown in Fig. 2.

Coefficients $c A_{m, n}$ and $c D_{m, n}$ are up sampled and filtered. The sum of this reconstructed approximation and detail signals constitutes the original signal S.

The choice of mother wavelet plays a significant role in time frequency analysis. This selection is strongly dependent on signal behavior in various conditions. There are many types of mother wavelet such as Harr, Daubechies, Coiflet and Symmlet. In this paper all wavelets, introduced in Wavelet Toolbox of MATLAB software are used for decomposition of signals. The best answer is obtained with "symmlet_1" mother wavelet. This has the best correlations with decomposition signals and is chosen in this work. Results with other wavelet and features as examples are shown in Appendix.

\section{SIMULATION RESULTS FOR FEATURE EXTRACTION}

A real primary $20 \mathrm{kV}$ distribution feeder (shown in Fig. 3) has been used to generate data for different events. Real data has been used for feeders, loads and transformers. The feeder information is included in Appendix. Ground fault, load and capacitor switching and no load energizing of transformer are simulated by ATPEMTP program. Three phase currents are recorded in the $\mathrm{HV} / \mathrm{MV}$ substation with a sampling rate of $20 \mathrm{kHz}$. For line and load model, $\pi$ model and load frequency model (CIGRE) are used respectively. BCTRAN model is used for transformer in fault, load and capacitor switching simulation and saturable transformer model is used for simulation of inrush current [21].

Magnetizing curve is approximated as two-linearized sections and is used for saturable transformer model. In the following subsections the results of simulation studies are presented.

Load switching: With load switching on the secondary side of the distribution transformers, the currents are recorded for different locations and different switching times. An illustrative example of load switching curve is shown in Fig. 4.

Capacitor switching: In the first case a capacitor of rating $\frac{2}{3} Q$ is connected at $\frac{2}{3}$ of the feeder length from the supply end. For the second case, a capacitor of rating $\frac{1}{2} Q$ is located at $\frac{2}{3}$ of feeder length and finally for the third case, a capacitor of rating $\frac{1}{2} Q$ is located at the end of the feeder, where $Q$ is the total reactive power load on the feeder. The three phase currents are recorded for different time switching in each case. Typical results for feeder currents after capacitor switching are shown in Fig. 5.

Ground fault: Fault current in the feeder in response to a single phase fault is shown in Fig. 6. It can be seen that the time between the break of the conductor and contact with the ground is very short. These currents are recorded for various locations, times and fault resistances.

Inrush current: Many types of inrush currents are recorded for different switching times and residual flux. An example of inrush current is shown in Fig. 7.

\section{PROPOSED PROCEDURE}

Wavelet transform with mother wavelet symmlet_1 is used for classification of transient phenomena. After decomposition of the phase currents for each cycle, sum of 


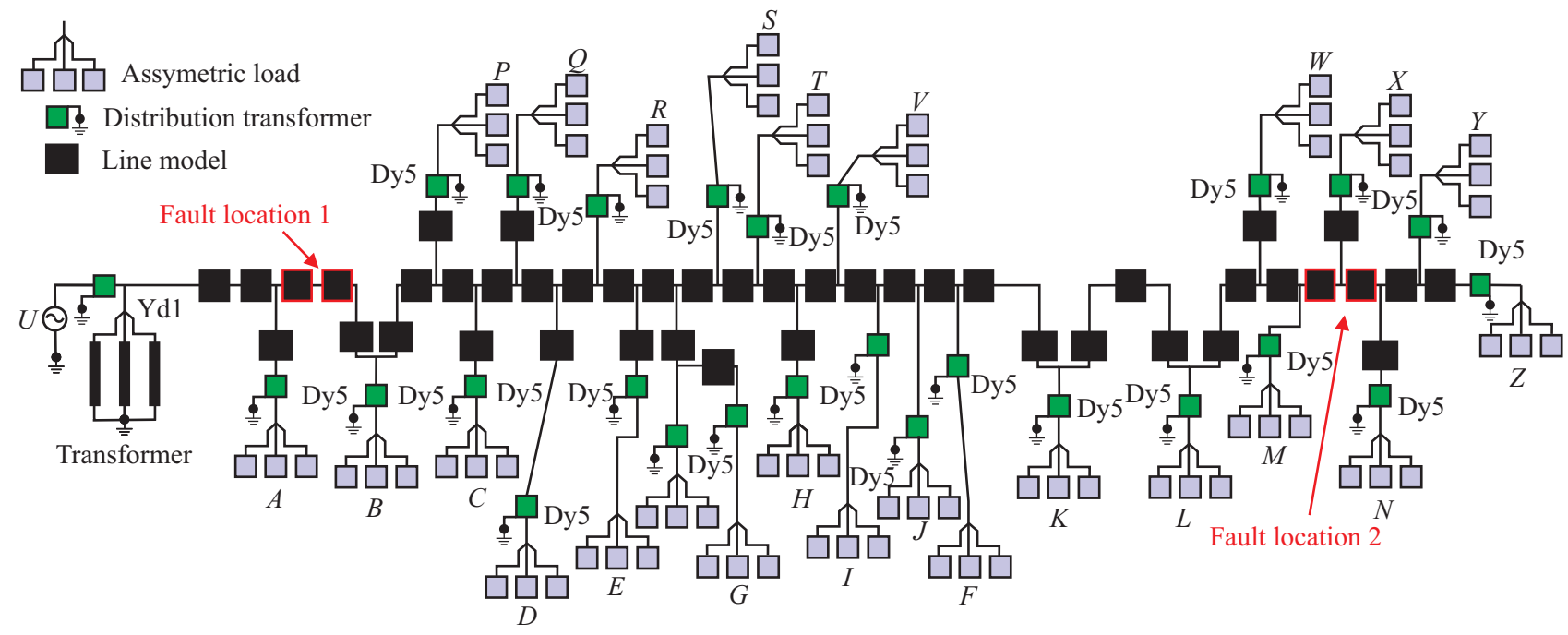

Fig. 3. Simulated $20 \mathrm{kV}$ distribution system
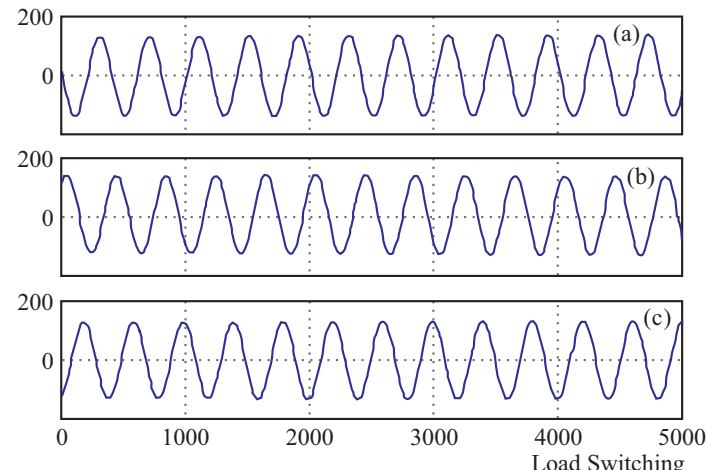

Fig. 4. Typical three phases load switching current

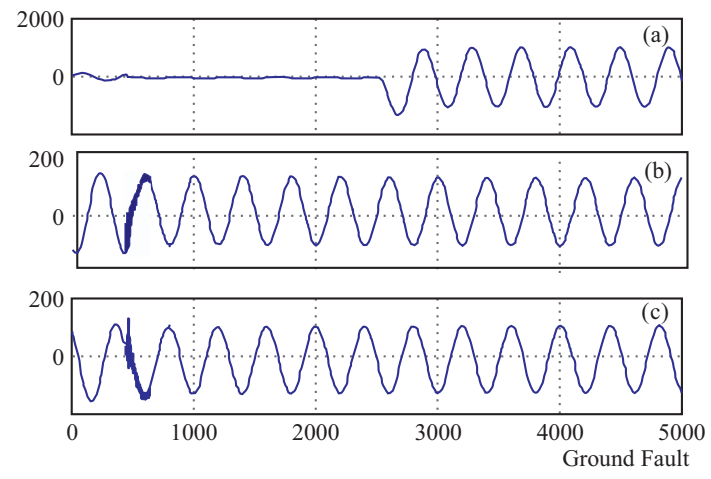

Fig. 6. Typical single phase ground fault currents

absolute $d 6$ coefficients in each cycle are used as suitable features for discrimination. As explained in Section 3, symmlet_1 mother wavelet and $|c d 6|$ summations in each cycle were chosen by trial and error by many tests with various mother wavelets and features. Decomposition of one-phase current in typical three phase switching using wavelet transform in Figs. 8-11.

Using many simulations and decomposition of three phase currents in each test, sum of the absolute of detail-

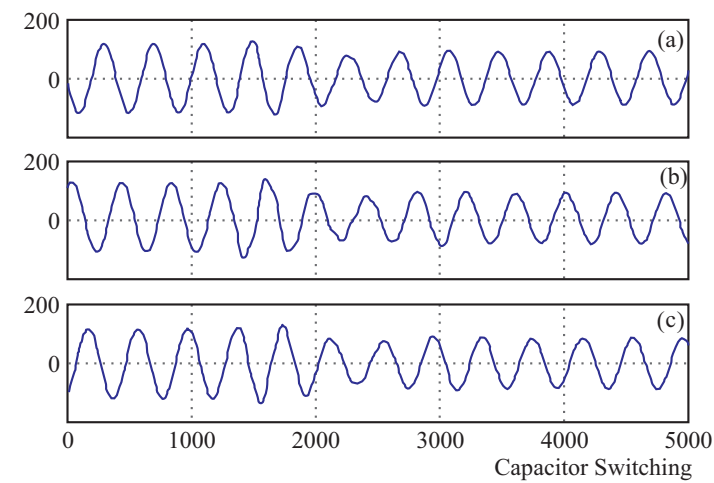

Fig. 5. Typical three phase capacitor switching currents

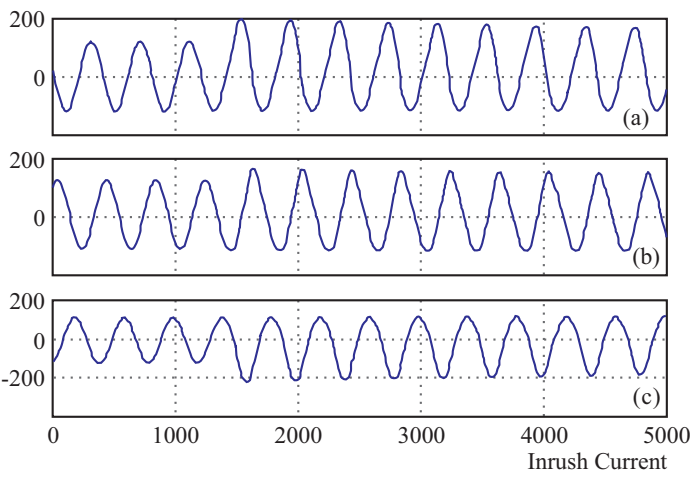

Fig. 7. Typical three phase inrush currents

6 in wavelet transform for three phase currents are proposed for classification of transient phenomena in distribution systems.

Shapes of the absolute of detail-6 summations in each cycle for capacitor switching, load switching, single phase to ground faults and inrush currents versus number of cycles are shown in Figs. 12-15.

As shown in these figures, $|c d 6|$ summation of three phase current in capacitor switching has a negative sharp 


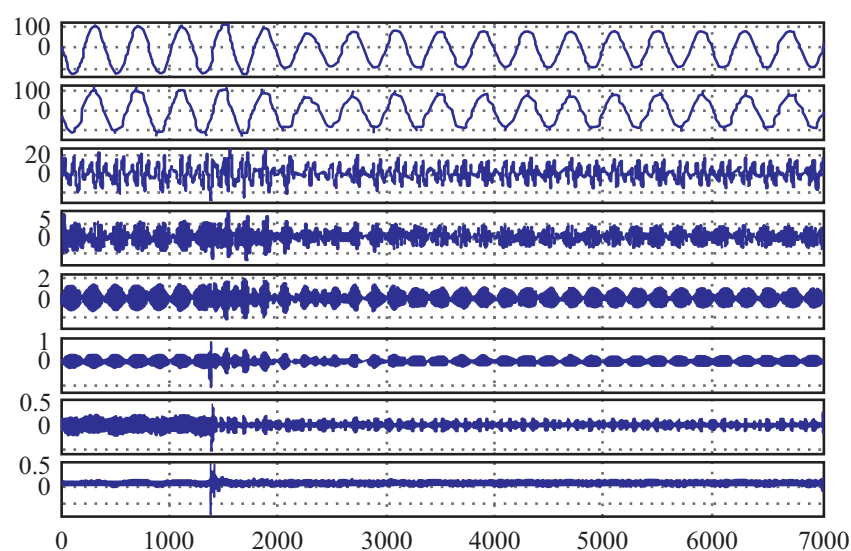

Fig. 8. Decomposition of phase A in typical three-phase capacitor switching using wavelet transform

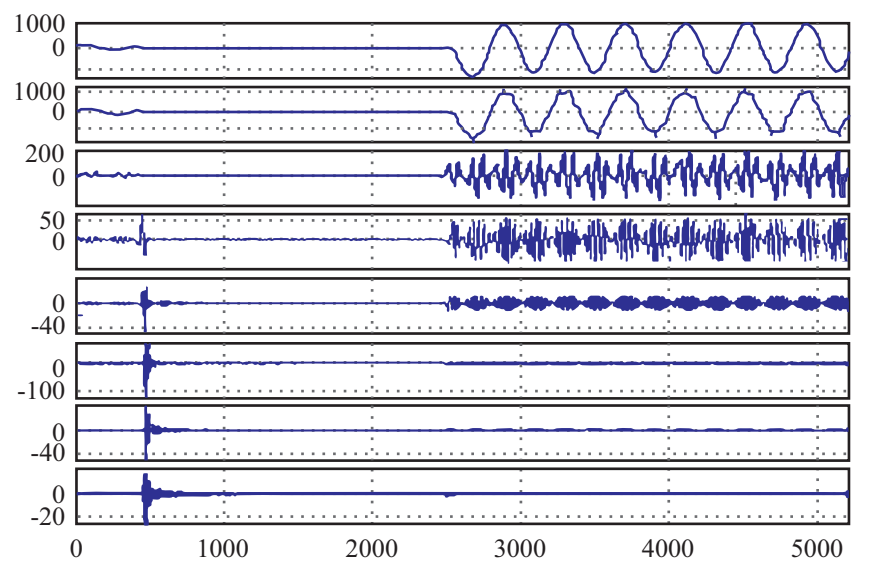

Fig. 10. Decomposition of phase A in typical three-phase single phase to ground fault using wavelet transform

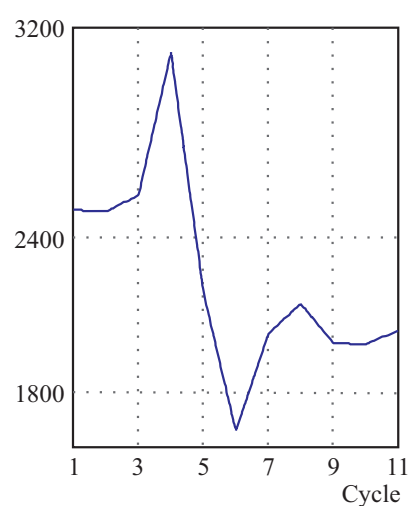

Fig. 12. Sum of $|c d 6|$ in wavelet transform for three phase capacitor switching

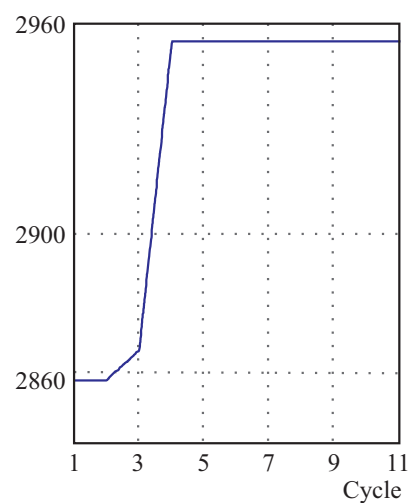

Fig. 13. Sum of $|c d 6|$ in wavelet transform for three phase load switching slope after switching action. Load switching has the constant level in cycles after switching action and ground fault has approximately constant level with a very slow slope after fault occurrence. It is seen in Fig. 15, that the $|c d 6|$ summation for three phase currents after switching of no load transformer (inrush current) is similar to an exponential function.

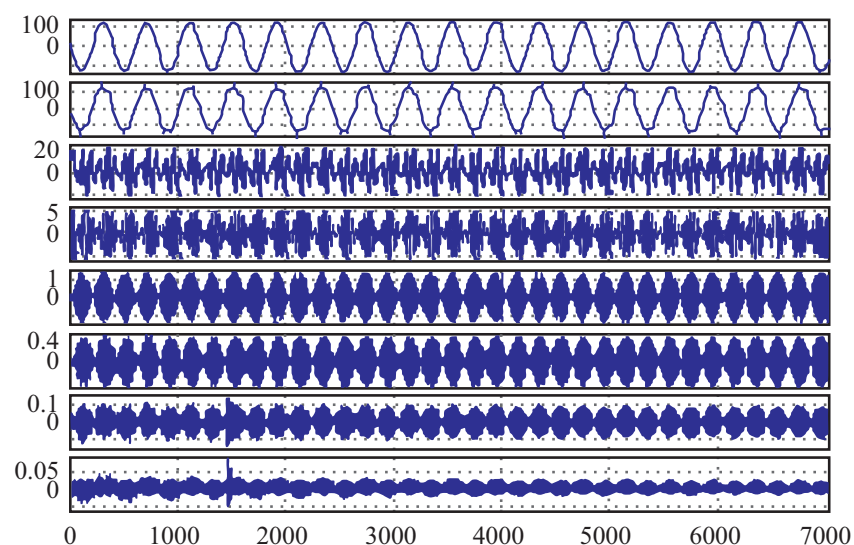

Fig. 9. Decomposition of phase A in typical load switching using wavelet transform

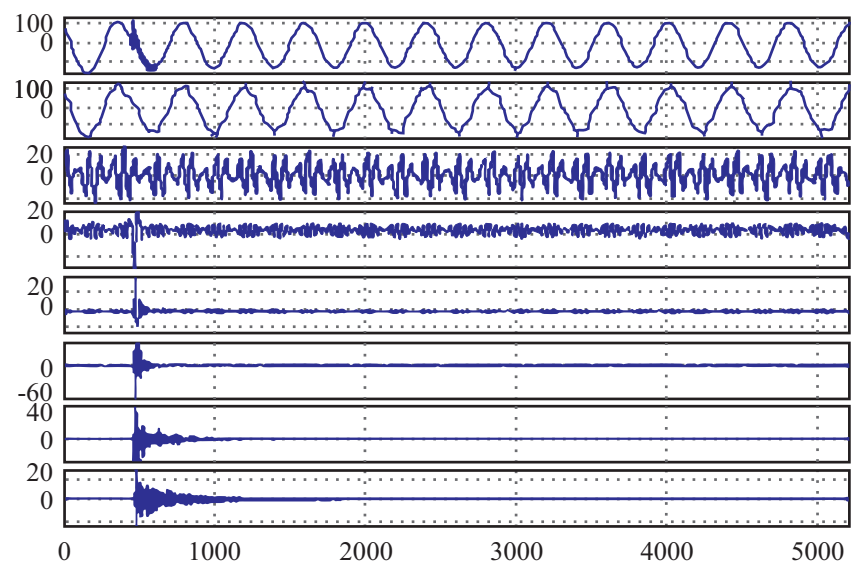

Fig. 11. Decomposition of phase A in typical three-phase inrush current using wavelet transform

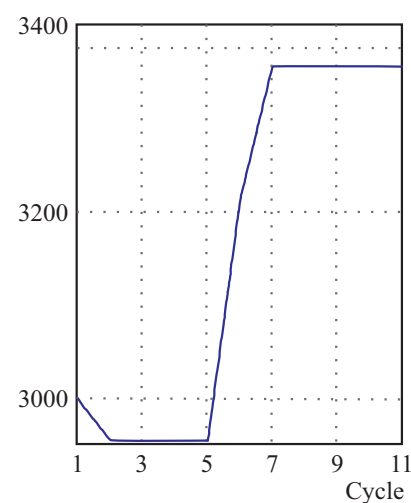

Fig. 14. Sum of $|c d 6|$ in wavelet transform for single phase to ground fault

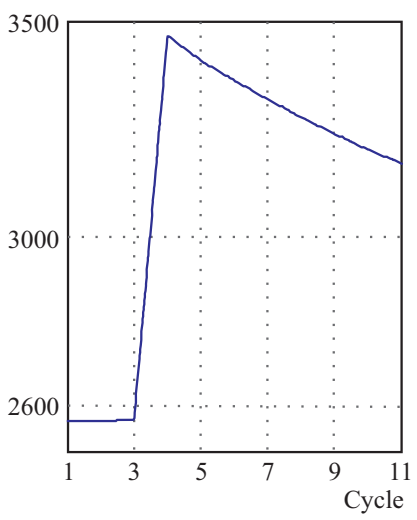

Fig. 15. Sum of $|c d 6|$ in wavelet transform for three-phase inrush current
The proposed algorithm for classification of these transient phenomena is shown in Fig. 16.

\section{TEST RESULTS}

Software has been developed based on the proposed algorithm. For the verification of the algorithm many sim- 


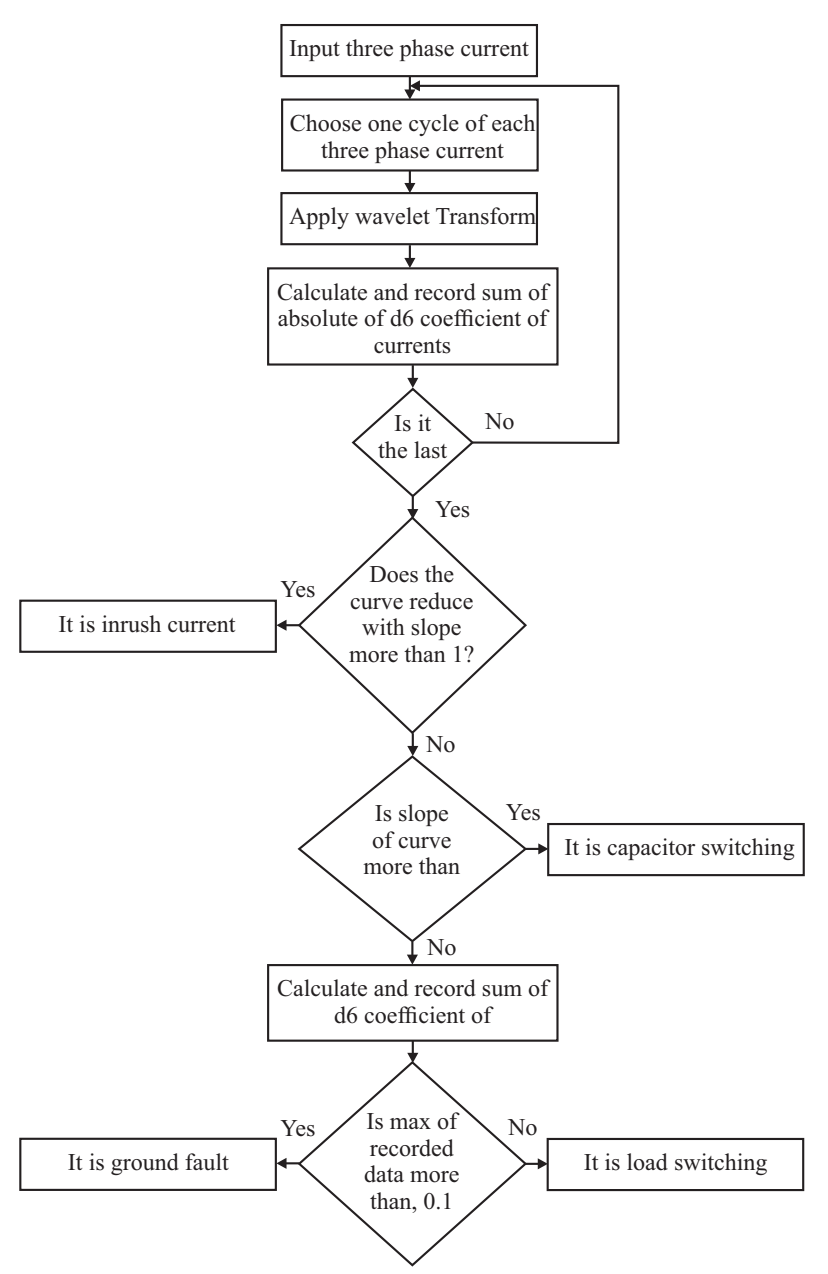

Fig. 16. Flow chart of proposed algorithm

ulation studies have been carried out using EMTP to obtain various transient phenomena in a typical $20 \mathrm{kV}$ distribution feeder shown in Fig. 3. Data for tests are sampled for different kinds of load switching, capacitor switching, single phase to ground fault and inrush current. Case studies are summarized in Table 1. In all these cases the transient phenomena were classified successfully using the developed software.

\section{CONCLUSIONS}

An efficient technique for classification of transient phenomena on electric distribution system is described in this paper. The proposed technique is based on the decomposition of three phase currents recorded at the $\mathrm{HV} / \mathrm{MV}$ substation using wavelet transform and the summation of the absolute values of $d 6$ coefficients is used for the discrimination and classification of inrush current, ground fault, load and capacitor switching. The data is produced by simulation of a real network with EMTP program. Simulation results show that the proposed method is very effective in classifying various types of transient phenomena.
Table 1. Cases studied

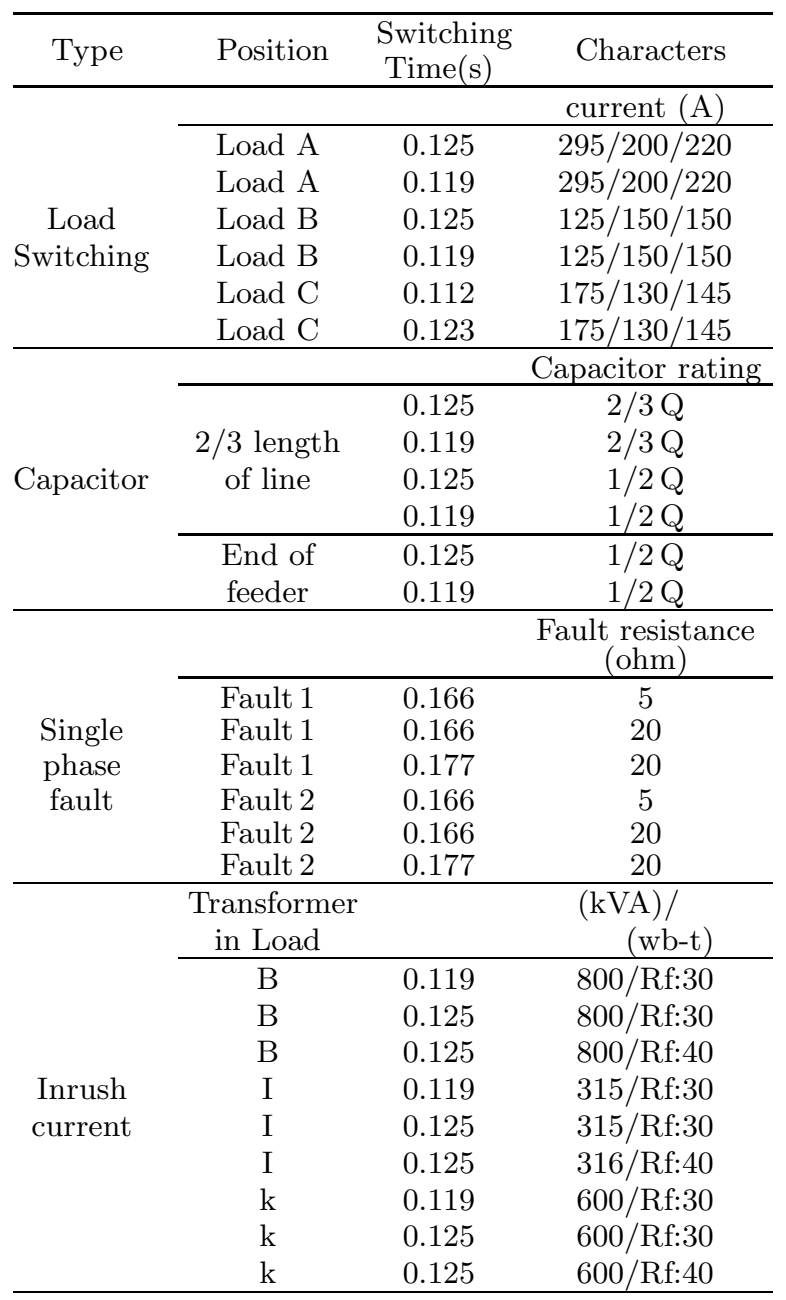

Q: Total reactive power Demand of feeder

Rf: Residual flux

\section{Appendix}

As explained in Section 2, selection of mother wavelet and features in signal processing are critical and important stages. They generally do not have unique solution and trial and error or heuristic methods are used to select them with respect to the produced signals in various conditions. In this research, all mother wavelets available in the MATLAB software with various features were tried to find the best wavelet and features for classification. As an example, results for two unsuccessful selections in the effort to find the best solution for classifying transients in electric distribution systems are presented in this Appendix. If bior3.1 and Sum of $|c d 6|$ are used as mother wavelet and a feature, then results will not be effective for classification of transients as seen in Figs. 17(a) to (d). As shown in these figures, the curves do not have any unique and specified variation for classification of signals. Load switching does not have constant level in cycles after switching action, ground fault has a negative sharp after fault occurrence and inrush current curve is similar to the capacitor switching curve. So the features with this mother wavelet cannot provide a successful classification. 

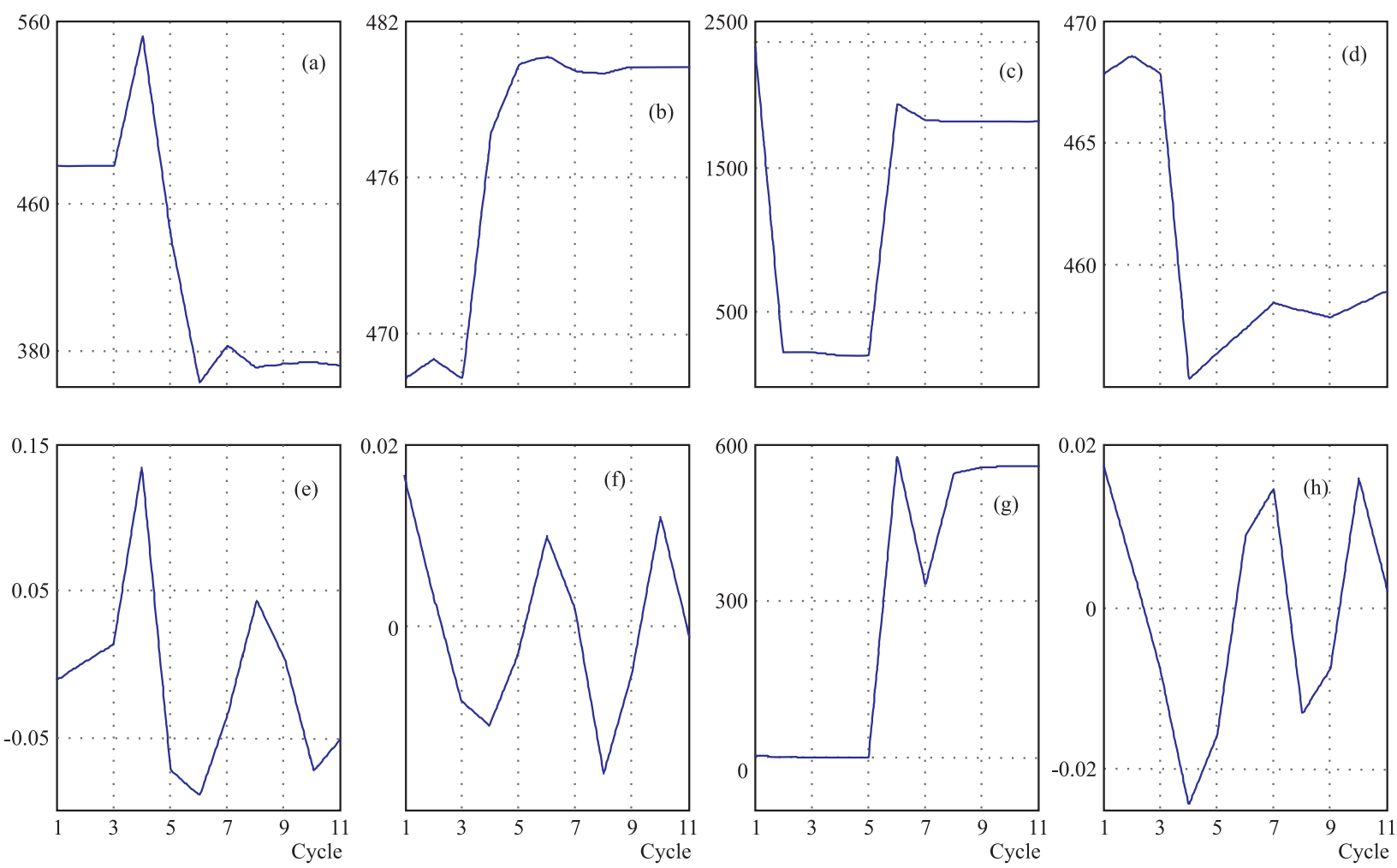

Fig. 17. Sum of $|c d 6|$ : (a) - capacitor switching, (b) - load switching, (c) - single phase to ground, (d) - inrush current; and sum of cd6 e: (e) - load switching, (f) - single phase to ground, (g) - inrush current

Table 2. Transformer data

\begin{tabular}{|c|c|c|c|c|c|c|c|}
\hline \multicolumn{2}{|c|}{ No. S(kVA) } & \multicolumn{2}{|c|}{ Connection N1/N2(kV) } & \multicolumn{2}{|c|}{$\mathrm{Uk} \% \operatorname{Poc}(\mathrm{W})$} & \multicolumn{2}{|c|}{$\operatorname{In} 1 \% \operatorname{Psc}(W)$} \\
\hline 1 & 30000 & Yd1 & $63 / 20$ & 14 & 22410 & 2.83 & 151247 \\
\hline 2 & 1250 & Dy5 & $20 /$ & 6 & 0 & 1.4 & 16 \\
\hline 3 & 1000 & D & $20 /$ & 6 & 750 & 4 & 13 \\
\hline 4 & 800 & D & $20 /$ & 6 & 1450 & 1.5 & 11000 \\
\hline 5 & 630 & Dy5 & $20 / 0.4$ & 6 & 1200 & 1.6 & 9300 \\
\hline 6 & 500 & Dy & $20 / 0.4$ & 6 & 1000 & 1.7 & 7800 \\
\hline 7 & 400 & Dy5 & $20 / 0.4$ & 6 & 85 & 1.8 & 6450 \\
\hline 8 & 315 & Dy 5 & $20 / 0.4$ & 6 & 72 & 2.0 & 5400 \\
\hline 9 & 250 & Dy & $20 / 0.4$ & 6 & 65 & 2.3 & 4450 \\
\hline 10 & 100 & Dy5 & $20 / 0.4$ & 6 & 340 & 2.6 & 2150 \\
\hline 11 & 50 & Dy5 & $20 / 0.4$ & 6 & 210 & 2.8 & 1250 \\
\hline
\end{tabular}

If the criterion of feature extraction changes, the results are not effective for discrimination of transient phenomena. For example if sum of cd6 is used instead of - cd6with the same mother wavelet (sym1), results will be as shown in Figs. 17(e) to (g). As shown in these figures, the selected feature is not suitable for classification of transient events.

$\underline{\text { Configuration of phases and further data: }}$

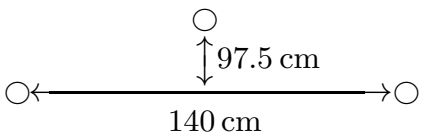

$R=0.509 \Omega / \mathrm{km}, \quad X=0.3561 \Omega / \mathrm{km}$,

Outside radius of conductor $=0.549 \mathrm{~cm}$,

Height of pole $=12 \mathrm{~m}$,

Sag in mid span $=2.32 \mathrm{~m}$. Constant parameters of the CIGRE load model usually considered in the EMTP program are $A=0.073, B=6.7, C=0.74$.

Table 3. Load data

\begin{tabular}{ccccccc}
\hline No. & $\begin{array}{c}\text { Load } \\
\text { name }\end{array}$ & $\begin{array}{c}\text { Ia } \\
(\mathrm{A})\end{array}$ & $\begin{array}{c}\mathrm{Ib} \\
(\mathrm{A})\end{array}$ & $\begin{array}{c}\text { Ic } \\
(\mathrm{A})\end{array}$ & $\begin{array}{c}\text { In } \\
(\mathrm{A})\end{array}$ & $\begin{array}{c}\text { Connected } \\
\text { transformer } \\
(\mathrm{kVA})\end{array}$ \\
\hline 1 & $\mathrm{~A}$ & 115 & 78 & 110 & 90 & 630 \\
2 & $\mathrm{~B}$ & 295 & 200 & 220 & 165 & 800 \\
3 & $\mathrm{C}$ & 40 & 60 & 55 & 0 & 500 \\
4 & $\mathrm{D}$ & 200 & 250 & 220 & 0 & 1250 \\
5 & $\mathrm{E}$ & 40 & 40 & 40 & 8 & 315 \\
6 & $\mathrm{~F}$ & 20 & 25 & 25 & 10 & 250 \\
7 & $\mathrm{G}$ & 80 & 50 & 40 & 0 & 100 \\
8 & $\mathrm{H}$ & 85 & 40 & 70 & 40 & 500 \\
9 & $\mathrm{I}$ & 145 & 130 & 120 & 40 & 315 \\
10 & $\mathrm{~J}$ & 205 & 180 & 205 & 65 & 500 \\
11 & $\mathrm{~K}$ & 125 & 100 & 105 & 25 & 630 \\
12 & $\mathrm{~L}$ & 30 & 60 & 50 & 20 & 800 \\
13 & $\mathrm{M}$ & 65 & 55 & 55 & 25 & 315 \\
14 & $\mathrm{~N}$ & 155 & 140 & 105 & 99 & 630 \\
15 & $\mathrm{P}$ & 60 & 55 & 55 & 17 & 250 \\
16 & $\mathrm{Q}$ & 33 & 57 & 45 & 32 & 315 \\
17 & $\mathrm{R}$ & 5 & 20 & 20 & 15 & 100 \\
18 & $\mathrm{~S}$ & 60 & 65 & 75 & 25 & 500 \\
19 & $\mathrm{~T}$ & 25 & 65 & 60 & 35 & 250 \\
20 & $\mathrm{~V}$ & 80 & 85 & 75 & 28 & 315 \\
21 & $\mathrm{~W}$ & 15 & 15 & 15 & 5 & 100 \\
22 & $\mathrm{X}$ & 175 & 130 & 145 & 45 & 315 \\
23 & $\mathrm{Y}$ & 165 & 175 & 150 & 55 & 800 \\
24 & $\mathrm{Z}$ & 125 & 150 & 150 & 45 & 1250 \\
\hline & & & & & &
\end{tabular}




\section{REFERENCES}

[1] COURY, D. V.-Dos SAntos, C. J.-TAVARES, M. C.: Transient Analysis Resulting from Shunt Capacitor Switching in an Actual Electrical Distribution System, Proc. 8th International Conference on Harmonics and Quality of Power, Vol. 1, 14-18, Oct 1998, pp. 292-297.

[2] MAK, S. T.: Propagation of Transient in a Distribution Network, IEEE Transactions on Power Delivery 8 No. 1 (Jan 1993), $337-343$.

[3] TUNGKANAWANICH, A.-KAWASAKI, Z. I.-MATSUURA, K.-KUNO, H. : Experimental Study for Transient Phenomena of Ground Fault on Distribution Lines based on Various Fault Causes, International Conference on Electric Power Engineering, PowerTech Budapest 99, 29 Aug-2 Sep 1999, p. 146.

[4] LI, H. Y.-BO, Z. Q.-CAUNCE, B.-POTTS, S.: A Fault Transient Comparison Technique for Multi-Ended Distribution Feeders, IEE Seventh International Conference on Developments in Power System Protection, 9-12 April 2001, pp. 153-156.

[5] FitzGerald, P.-BISHOP, P.-BO, Z. Q.-DENNING, L.-WELLER, G.-O'KEEFE, M.: A New Directional Relay for Distribution Network Protection using Transient Comparison Technique, IEE Seventh International Conference on Developments in Power System Protection, 9-12 April 2001, pp. 193-196.

[6] PERICOLO, P. P.-NIEBUR, D. : Discrimination of Capacitor Transients for Position Identification, IEEE Power Engineering Society Winter Meeting, 28 Jan. -1 Feb. 2001, vol. 2, pp. 872-877.

[7] SHAH, A. M.-BHALJA, B. R.: A New Approach to Digital Protection of Power Transformer using Support Vector Machine, Electrical and Computer Engineering (CCECE), 2011 24th Canadian Conference on, 2011, pp. 11-14, DOI: 10.1109/CCECE.2011.6030399.

[8] GREBE, T. E.: Application of Distribution System Capacitor Banks and their Impact on Power Quality, The 39th Annual Rural Electric Power Conference, 30 April-2 May 1995, pp. C3/1-C3/6.

[9] LI, Q.-CHAN, D. T. W. : Investigation of Transformer Inrush Current using a Dyadic Wavelet, Proc. of the International Conference on Energy Management and Power Delivery, 3-5 March 1998, vol. 2, pp. 426-429.

[10] LIU, X.--LIU, P.-CHENG, Sh. : A Wavelet Transform based Scheme for Power Transformer Inrush Identification, IEEE Power Engineering Society Winter Meeting, 23-27 Jan 2000, vol. 3, pp. 1862-1867.

[11] CHUANLI, Zh.-YIZHUANG, H.-XIAOXU, M.-WENZHE, L.-GUOXING, W.: A New Approach to Detect Transformer Inrush Current by Applying Wavelet Transform, Proceedings POWERCON'98 International Conference on Power System Technology, vol. 2, 18-21 Aug 1998, pp. 1040-1044.

[12] JIAO, Sh.-WANG, Sh.-ZHENG, G.: A New Approach to Identify Inrush Current based on Generalized S-Transform, Elec- trical Machines and Systems, 2008. ICEMS 2008. International Conference on, 2008, pp. 4317-4322.

[13] MOKRYANI, G.-HAGHIFAM, M.-R.-LATAFAT, H.-ALIPARAST, P.-ABDOLLAHY, A. : Detection of Inrush Current based on Wavelet Transform and LVQ Neural Network, Transmission and Distribution Conference and Exposition, 2010 IEEE PES, 2010, pp. 1-5, DOI: 10.1109/TDC.2010.5484413.

14] SLADE, P. G. : Vacuum Interrupters, the New Technology for Switching and Protecting Distribution Circuits, IEEE Transactions on Industry Applications 33 No. 6 (Nov-Dec 1997), 1501-1511.

15] LuBKeman, D. L.-FAllon, C. D.-GIRGIS, A. A.: Unsupervised Learning Strategies for the Detection and Classification of Transient Phenomena on Electric Power Distribution Systems, Proc. of the First International Forum on Applications of Neural Networks to Power Systems, 23-26 July 1991, pp. 107-111.

16] ROBERTSON, D. C.-CAMPS, O. I.-MAYER, J. S.-GISH, W. B. : Wavelet and Electromagnetic Power System Transient, IEEE Transactions on Power Delivery 11 No. 2 (Apr 1996), 1050-1058.

17] SANTOSO, S.-POWERS, E. J.-GRADY, W. M.-HOFMANN, P.: Power Quality Assessment via Wavelet Transform Analysis, IEEE Transactions on Power Delivery 11 No. 2 (Apr 1996), 924-930.

18] TONGXIN, Zh.-MAKRAM, E. B.-GIRGIS, A. A.: Power System Transient and Harmonic Studies using Wavelet Transform, IEEE Transactions on Power Delivery 14 No. 4 (Oct 1999), 1461-1468.

19] MALlAT, S. : A Wavelet Tour of Signal Processing, Academic Press, 1998.

[20] GOSWAMI, J. C.: Fundamentals of Wavelets, John Wiley\&Sons, 1999.

[21] Leuven EMTP center, Alternative Transient Program Rule Book, last revision date July 1987.

Received 15 July 2012

Ali-Reza Sedighi (M'09) was born in Anarak, Iran, on September 15, 1968. He received the BS, degree in electrical engineering from Isfahan University of Technology, Isfahan, Iran in 1990 and MSc and $\mathrm{PhD}$ in electrical engineering from Tarbiat Modarres University, Tehran, Iran, in 1994, 2004 respectively all in power engineering. Currently, he is an Associate Professor in the Power System Engineering Group at Department of Electrical \& computer Engineering, Yazd University, Yazd, IRAN. His main research interests are Electric Distribution Systems, Signal Processing in Electrical Power Systems and Power System Intelligent Control. Dr. Sedighi is Director of Power Quality Research Group in Engineering Research Centre of Yazd University since 2009 up to now. 